\title{
O CUIDADO DE SI EM MICHEL FOUCAULT: REFLEXÕES PARA A EDUCAÇÃO FíSICA
}

\author{
SELF-CARE IN MICHEL FOUCAULT: REFLECTIONS FOR \\ PHYSICAL EDUCATION
}

\section{EL CUIDADO DE SÍ EN MICHEL FOUCAULT: REFLEXIONES PARA LA EDUCACIÓN FÍSICA}

Maria Isabel Brandão de Souza Mendes*, Jacques Gleyse ${ }^{* *}$

\section{Palavras-chave} Atençao à saúde. Corpo humano. Filosofia
Resumo: Neste artigo discute-se sobre o cuidado de si em obras de Michel Foucault, buscando tecer reflexões para a Educação Física. Destacamos elementos associados ao cuidado de si, como a imagem do rodopio, no sentido de problematizar na atualidade os cuidados com o corpo em busca de saúde com base em padronizações e na obediência incondicional a esses ditames que são impostos de múltiplas maneiras. Conclui-se que esta pesquisa poderá ampliar o debate epistemológico na Educação Física, uma vez que o cuidado de si religa saberes e práticas e pode ser reconhecido como fundamento filosófico.

Abstract: This article discusses self-care in the works of Michel Foucault, seeking to conduct reflection for Physical Education. We point out elements associated with selfcare, such as the image of spinning, to discuss body care for health today, based on standardization and unconditional obedience to the dictates imposed in multiple ways. This research may expand the epistemological debate in Physical Education, since selfcare reconnects knowledges and practices and can be recognized as a philosophical foundation.

Resumen: En este artículo se discute sobre el cuidado de sí en la obra de Michel Foucault, tratando de tejer reflexiones para la Educación Física. Resaltamos elementos asociados al cuidado de sí, como la imagen de girar sobre sí mismo, en el sentido de problematizar hoy el cuidado del cuerpo con vistas a la salud, teniendo como base la estandarización y la obediencia incondicional a esos dictámenes que son impuestos de múltiples formas. Llegamos a la conclusión de que esta investigación puede ampliar el debate epistemológico en Educación Física, ya que el cuidado de sí reconecta conocimientos y prácticas y puede ser reconocido como fundamento filosófico.
*Universidade Federal do Rio Grande do Norte. Natal, RN, Brasil.

E-mail: isabelmendes@ufrnet.br

**Université de Montpellier. Montpellier, França.

E-mail: jacques.gleyse@ orange.fr

Recebido em: 16-06-2014

Aprovado em: 18-10-2014

(c) (1) (8) Licence

Creative Commom 


\section{INTRODUÇÃO}

A atividade epistemológica é necessária para qualquer área do conhecimento, haja vista que contribui com a interrogação e revisão de conceitos, teorias, métodos, problemáticas de investigação, corpo de conhecimentos que definem determinada área, relação entre os diversos saberes, limites do próprio conhecimento, linguagem, dentre outros questionamentos.

Com o reconhecimento de que a atividade epistemológica possui caráter vivo, provisório e processual, como propõe Fernsterseifer (2006), torna-se relevante ressaltar que sempre existe a necessidade de interrogar fundamentos filosóficos e científicos que podem contribuir com a organização do conhecimento da Educação Física. Faz-se necessário, então, desenvolver pesquisas, numa tentativa de buscar definições conceituais para as práticas acadêmica e profissional ou ainda aprofundar temáticas que já se fazem presentes.

Desse modo, no intuito de contribuir com os estudos epistemológicos direcionados à Educação Física desenvolvidos com foco nos estudos do corpo, pretendemos contribuir com 0 debate argumentativo sobre o conhecimento da área nesta pesquisa.

Certas pesquisas na Educação Física brasileira realizadas em diferentes cenários sócio-históricos e epistemológicos demonstram discursos e práticas educativas sobre corpo e saúde que exacerbam certo culto ao corpo, o padrão de estilo de vida ativo e reforçam a ideia do ser saudável ideal (CARVALHO, 1995; SOARES, 2001; SILVA, 2001; FRAGA, 2006; GOMES, 2009, BEZERRA, 2012).

O projeto de alcançar o ser saudável ideal propagado na sociedade pelos discursos biomédicos tem como intuito instaurar na vida humana a positividade da saúde. Surgiu no final do século XVIII, como ressalta Foucault (2001), ao fazer referência à medicina europeia. Para atingir seus objetivos, então, a medicina moderna não se limitava a um conjunto de técnicas da cura e do saber exigido; abrangia, ainda, um conhecimento do ser humano saudável, um ser humano modelo, livre de doença. Com essa postura normativa, não era mais cabível aos médicos unicamente aconselhar sobre a vida em equilíbrio, eles passaram a pretender regular as relações físicas e morais dos indivíduos e da sociedade.

A partir do final do século XVIII, com a instauração da ideia do ser saudável ideal, o corpo humano é visto de forma fragmentada. 0 biopoder se instaura, e o corpo que vive, suporte do nascimento, da morte, da longevidade e da saúde, é controlado para ser inserido no campo produtivo e econômico, servindo, desse modo, para o desenvolvimento da sociedade industrial. As estratégias biopolíticas desejam intervir sobre a maneira de viver, para ampliar a vida, controlar os acidentes, o aleatório, as deficiências. O poder sobre a vida se propõe instaurar uma administração calculista da existência (FOUCAULT, 1988).

Diante das estratégias biopolíticas que permeiam certos cenários educativos da Educação Física brasileira, há a necessidade de continuar a contribuir com o debate argumentativo sobre o conhecimento da área, com vistas a problematizar os cuidados com o corpo em busca de saúde com base em padronizações de movimentos. Como mostra Gleyse (1997), ao realizar uma arqueologia da racionalização instrumental do corpo, não é de hoje que movimento humano e saúde apresentam associações, considerando-se as referências do autor aos filósofos e aos médicos antigos. 
Essa associação antiga entre movimento humano e saúde é reforçada quando o autor (GLEYSE, 2011) faz uma análise dos arquivos antigos da Faculdade de Medicina de Montpellier, considerada uma das primeiras Faculdades de Medicina do ocidente. Ele identifica que os discursos analisados do século XVI, apesar de reabilitarem costumes dos médicos gregos e árabes, apresentam uma ruptura com as visões da Antiguidade de ser humano e de mundo e contribuíram com a fabricação do corpo por meio da ginástica (GLEYSE, 2011). A fabricação do corpo, como pode ser observado nos estudos de Gleyse (1997), faz parte da tradição da Educação Física francesa, mas também influenciou a tradição da Educação Física brasileira, como pode ser observado em certos estudos do nosso país sobre corpo (SOARES, 2001; NÓBREGA, 2000; SILVA, 2001).

Diante da necessidade de problematizar os cuidados com o corpo em busca de saúde com base em padronizações na atualidade, esta pesquisa se propõe a contribuir com as discussões que estabelecem relações da Educação Física com a temática do corpo, tendo como objeto de estudo o conceito de "cuidado de si", com base nos estudos de Michel Foucault. Notadamente, escritos que estão relacionados à análise da constituição de si mesmo como sujeito, tendo como foco o conceito de "cuidado de si": volumes II e III da História da Sexualidade: o uso dos prazeres e o cuidado de si (FOUCAULT, 1984; 1985); Ditos e Escritos V (FOUCAULT, 2012a; 2012b; 2012c) e A hermenêutica do sujeito (FOUCAULT, 2006).

Considerando-se a relevância do conceito de "cuidado de si" para as reflexões sobre os cuidados do corpo em busca de saúde, foi realizado um levantamento no Brasil nas bases de dados LiLACS e SciELO e na França na base de dados Revues.org'. Foi identificado que esse conceito tem contribuído com o desenvolvimento de pesquisas em várias áreas do conhecimento. Porém, na Educação Física brasileira e francesa, as pesquisas que tematizam o conceito de "cuidado de si" ainda são escassas. Na Educação Física brasileira foi identificado o estudo de Bossle (2008) e na Educação Física francesa nenhum estudo foi identificado.

Bossle (2008) faz uma reflexão sobre o cuidado de si, buscando articulação com outros pensamentos, como os de Baudrillard, Deleuze e Bauman. Seu intuito é tecer uma discussão sobre o cuidado de si propondo uma mediação entre o personal trainer e seu cliente. Com relação a esse estudo, algumas inquietações afloram, mais especificamente no que tange à transposição de elementos do cuidado de si para a relação entre o personal trainer e seu cliente. Mas, como a autora mesmo destaca, as discussões sobre essa temática são escassas, o que a faz demonstrar que se trata de uma reflexão inacabada.

Uma das hipóteses dessa ausência de discussões sobre o cuidado de si pode ser 0 fato de que os estudos na Educação Física que buscam contribuições em obras de Michel Foucault têm enfatizado outros conceitos tematizados por esse filósofo francês, como o conceito de disciplinarização, biopoder e biopolítica, por exemplo.

Portanto, diante da necessidade de aprofundamentos sobre o conceito de "cuidado de si", elegemos, então, as seguintes questões de estudo:

1 No Brasil: Resende (2008); Candiotto (2008; 2010); Machado; Lavrador (2009); Silva et al (2009); Vargas; Ramos (2010); Castro; Viana; Bara (2010); Farina et al. (2010); Leite; Aragão (2010); Seixas; Birman (2012), Palmeira; Ferreira (2012); Ayres (2004). Na França: Le Blay (2013); Hénaff (2011); Goetz (2004); Mozère (2004). 
- Que saberes e práticas estão associados ao "cuidado de si" nos três momentos abordados por Michel Foucault: o socrático-platônico, a idade de ouro nos séculos I e II d.C. e na passagem aos séculos IV-V?

- Que contribuições essas reflexões podem trazer para a Educação Física?

Iniciamos a nossa discussão trazendo elementos sobre a emergência do conceito de cuidado de si. Posteriormente, apresentamos uma síntese de saberes e práticas relacionada ao cuidado de si nos três momentos abordados por Michel Foucault: o socrático-platônico, a idade de ouro nos séculos I e II d.C. e na passagem aos séculos IV e V d.C. Para finalizar, a partir das discussões realizadas apontamos reflexões relevantes para a Educação Física que podem colaborar para problematizar os cuidados com o corpo em busca de saúde pautados no culto ao corpo, num padrão de estilo de vida ativo e que reforçam a ideologia do ser saudável. Nas considerações finais enfatiza-se que as discussões tecidas podem colaborar com o debate epistemológico da Educação Física no Brasil e no exterior.

\section{SOBRE A EMERGÊNCIA DO CUIDADO DE SI}

Como destaca a filósofa brasileira Muchail (2004), uma das tradutoras de livros de Michel Foucault, ele mergulhava em escritos do passado para refletir sobre problemáticas contemporâneas, e sua trajetória acadêmica é reconhecida por vários estudiosos de suas obras a partir de três momentos que se relacionam entre si.

O primeiro momento é denominado de Período da Arqueologia e está relacionado às questões relativas à constituição dos saberes, ao campo epistemológico. 0 segundo momento é denominado de Período da Genealogia e está relacionado aos mecanismos de poder, ao campo político. O terceiro momento, denominado de Constituição do Sujeito Ético, está relacionado às questões relativas à análise da constituição de si mesmo como sujeito, ao campo ético.

Num texto intitulado Les archives Foucault à Berkeley, Alain Beaulieu (2013, p.1) mostra que esse terceiro momento da trajetória acadêmica de Michel Foucault foi influenciado pelos encontros que teve na Califórnia, como pode ser visto na citação a seguir:

0 ambiente californiano, liberal e esquerdista, estilizado e revolucionário, oferecia à Foucault o que Ihe faltava no Collège de France e a sua institucionalização de saberes, quer dizer, um espaço que favoreça simultaneamente a liberdade da fala, a liberdade acadêmica, a proximidade com os estudantes e as práticas minoritárias. Não há dúvida de que esses encontros e essas experiências tiveram um efeito direto sobre a orientação e o desenvolvimento dos temas abordados pelo último Foucault (releitura da tradição liberal, cuidado de si, ética e estética da existência, etc.). Os meios acadêmicos da costa oeste americana tornaram-se, assim, testemunhas privilegiadas da evolução de pensamento foucaultiano que, por sua vez é alimentado desse meio de vida².

O conceito de "cuidado de si" emerge nesse terceiro momento de sua trajetória acadêmica e está relacionado à realização de uma genealogia do sujeito, como mostra Eribon (1990) ao mencionar itens relacionados à escrita da História da sexualidade.

2 Tradução dos autores. 
Neste contexto, Michel Foucault aponta resistências às relações de poder. Como ele destaca: "[...] nas relações de poder, há necessariamente possibilidade de resistência, pois se não houvesse possibilidade de resistência - de resistência violenta, de fuga, de subterfúgios, de estratégias que invertam a situação -, não haveria de forma alguma relações de poder" (FOUCAULT, 2012a, p. 277).

Esse filósofo se importava em descobrir por meio de que jogos de verdade o ser humano se conheceu novamente como homem de desejo (ERIBON, 1990).

$\mathrm{Na}$ época de revisar os escritos sobre o cuidado de si, Michel Foucault estava muito doente e para ele "[...] o problema que se tornou o seu é a 'estilização da existência', a "estética da vida"' (ERIBON, 1990, p. 310). Seu interesse era de que a vida de cada um se tornasse uma obra de arte.

Para discorrer sobre as transformações do conceito de "cuidado de si" na tradição ocidental, Foucault (2006) investiga três momentos: o socrático-platônico, a idade de ouro nos séculos I e II d.C. e na passagem aos séculos IV e V d.C. Quando apresenta os resultados de suas análises, o filósofo demonstra saberes e práticas associados ao "cuidado de si" em cada momento desses, relacionando-os às formas de governo que se diferenciam de um período para outro.

A ideia de governo, para Foucault (1997), está relacionada às técnicas e aos modos de guiar a conduta dos seres humanos. As modernas formas de governabilidade, que surgem a partir do processo de secularização das ações e dos discursos construídos na pastoral cristã, estão relacionadas à ideia de governo atrelada à obediência incondicional aos preceitos médicos.

Na pastoral cristã, a ideia de governo refere-se a uma espécie de vigilância do sujeito sobre si mesmo atrelada à obediência incondicional ao mestre, ao exame ininterrupto e à confissão exaustiva (FOUCAULT, 1997).

Entretanto, Foucault $(2004,2008)$, ao se referir aos saberes e práticas do cuidado de si da Antiguidade greco-romana associados ao governo de si, demonstra que nesse cenário educativo colocava-se à disposição uma série de auxílios, que poderiam ser utilizados em caso de necessidade, colaborando com a constituição de uma relação autônoma.

Diante do debate sobre as artes de governo é interessante a discussão que Fonseca (2008) tece sobre a vida governada e o governo de si. Esse debate nos provoca a estar atentos sobre formas de como não ser governado por ditames que são impostos. 0 autor defende que a ideia de não ser governado está associada à recusa dessas imposições e à possibilidade de limitá-las, recusá-las ou até mesmo transformá-las.

\section{SABERES E PRÁTICAS RELACIONADAS AO CUIDADO DE SI}

O Quadro 1 apresenta uma síntese de saberes e práticas relacionados ao cuidado de si predominantes nos três momentos abordados por Michel Foucault: o socrático-platônico, a idade de ouro nos séculos I e II d.C. e na passagem aos séculos IV e V d. C. 
Quadro 1 - Relação entre saberes e práticas relacionados ao cuidado de si predominantes em cada período

\begin{tabular}{|c|c|c|}
\hline $\begin{array}{l}\text { Momento sócio- } \\
\text { histórico }\end{array}$ & Saberes & Práticas \\
\hline $\begin{array}{l}\text { Momento socrático- } \\
\text { platônico }\end{array}$ & $\begin{array}{l}\text { Ideias filosóficas } \\
\text { Sócrates } \\
\text { Platão } \\
\text { Texto Apologia de Sócrates } \\
\text { Textos de Alcebíades } \\
\text { Ideias médicas } \\
\text { Hipócrates } \\
\text { Coleção hipocrática }\end{array}$ & $\begin{array}{l}\text { - Técnicas de concentração } \\
\text { - De memorização do passado } \\
\text { - exame de consciência } \\
\text { - ritos de purificação } \\
\text { - técnicas de meditação } \\
\text { - técnica do retiro } \\
\text { - prática de resistência às tentações } \\
\text { - Preparação para o sonho (escutar música, respirar } \\
\text { perfumes, exame de consciência) } \\
\text { - Técnicas de respiração } \\
\text { Dieta / Regime } \\
\text { - Os exercícios } \\
\text { - Os alimentos } \\
\text { - As bebidas } \\
\text { - Os sonos } \\
\text { - As relações sexuais } \\
\text { - Práticas de liberdade (não escravidão) / temperança }\end{array}$ \\
\hline Idade de Ouro (I-II d.C) & $\begin{array}{l}\text { Ideias filosóficas } \\
\text { Filósofos da época helenística } \\
\text { (Epicuristas, cínicos e } \\
\text { estoicos) } \\
\text { Cartas de Sêneca } \\
\text { Marco Aurélio } \\
\text { Frontão } \\
\text { Plíneo } \\
\text { Epicuro } \\
\text { Epicteto } \\
\text { Ideias médicas } \\
\text { Galeno }\end{array}$ & $\begin{array}{l}\text { - Escuta (primeiro procedimento na ascese e na subjetivação } \\
\text { do discurso verdadeiro) } \\
\text { - Escrita (ênfase na época imperial)/ associada à meditação, } \\
\text { ao exercício do pensamento / tem função etopoiética = } \\
\text { operadora de transformação da verdade em etos } \\
\text { - Leitura } \\
\text { - Falar } \\
\text { - Meditação } \\
\text { - Memorização } \\
\text { - Exame de consciência } \\
\text { Dieta / Regime } \\
\text { - Os exercícios } \\
\text { - Os alimentos } \\
\text { - As bebidas } \\
\text { - Os sonos } \\
\text { - As relações sexuais } \\
\text { - Práticas de liberdade (e não escravidão) }\end{array}$ \\
\hline $\begin{array}{l}\text { Momento Cristão } \\
\text { (III - IV d. C.) }\end{array}$ & $\begin{array}{l}\text { Ideias religiosas } \\
\text { Textos cristãos } \\
\text { Traité de la virginité de } \\
\text { Gregório de Nisa }\end{array}$ & $\begin{array}{l}\text { Memória } \\
\text { Meditação } \\
\text { Exame de consciência } \\
\text { Escuta } \\
\text { Escrita } \\
\text { (Diferente do modelo helenístico) }\end{array}$ \\
\hline
\end{tabular}

Fonte: Quadro construído com base nos estudos de Foucault (1984, 1985, 2006, 2012a, 2012c).

O momento socrático-platônico é considerado o momento do surgimento do cuidado de si na reflexão filosófica. Cuidar de si significa ocupar-se consigo mesmo. Preocupar-se consigo. Neste período, cuidar de si está relacionado com conhecer-se, cuidar de si para cuidar dos outros, ou seja, para ser capaz de governar as cidades. Trata-se, então, de uma atividade política. Michel Foucault, quando se refere ao cuidado de si no momento socráticoplatônico, diz que é uma "[...] espécie de aguilhão que deve ser implantado na carne dos homens, cravado na sua existência" (FOUCAULT, 2006, p. 11). 
No Quadro 1 observamos que o cuidado de si no momento socrático-platônico é pautado em saberes filosóficos e médicos, destacando-se as ideias de Sócrates, Platão e Hipócrates. No que se refere às práticas, estas são destinadas aos jovens de elite. Observamos no Quadro 1 diversas técnicas que são destinadas aos jovens e que requerem concentração, como as de meditação, de memorização do passado, de exame de consciência, do retiro, de resistência às tentações, de respiração, de preparação para o sonho, e também o escutar música e o respirar perfumes. Há também os ritos de purificação, como podem ser identificados no livro A Hermenêutica do sujeito (FOUCAULT, 2006).

Além dessas práticas encontradas no momento socrático-platônico, nos deparamos com práticas relacionadas com a dieta, o regime, como pode ser identificado no livro História da sexualidade 2: o uso dos prazeres. Essas práticas estão associadas aos exercícios físicos, aos alimentos, às bebidas, ao sono e às relações sexuais. A preocupação com 0 regime refere-se ao modo de se conduzir a própria existência. Foucault, ao se referir ao regime, destaca que: "[...] não é para ser considerado como um corpo de regras universais e uniformes; é antes de mais nada, uma espécie de manual para reagir às situações diversas nas quais é possível encontrar-se; um tratado para ajustar o comportamento de acordo com as circunstâncias" (FOUCAULT, 1984, p. 135).

No contexto socrático-platônico há uma ressalva para uma prática refletida sobre si mesmo e não uma obediência nua ao saber do outro. É uma maneira de se constituir como sujeito. Deparamo-nos, então, com princípios estratégicos e não receitas imperativas, com práticas de liberdade e não de escravidão. Práticas permeadas pela temperança (FOUCAULT, 2012a).

Neste contexto, o conhecimento de si é o imperativo do cuidado de si e há três condições que o determinam: a primeira refere-se ao campo de aplicação que visa os jovens aristocratas destinados a exercer o poder e que devem ocupar-se consigo. A segunda refere-se ao objetivo de governar a cidade, ou seja, ocupar-se consigo a fim de exercer 0 poder ao qual se está destinado. E a terceira condição é a da sua forma principal, ou seja, o conhecimento de si. Ocupar-se consigo é conhecer-se (FOUCAULT, 2006).

O período que abrange os séculos I e II d.C. é reconhecido por Michel Foucault como a idade de ouro do cuidado de si e está relacionado às artes de viver. $\mathrm{O}$ cuidado de si é compreendido tanto como noção quanto como prática e como instituição. Há transformações no cuidado de si neste período. Há um deslocamento cronológico. Do final da adolescência passa-se para a vida adulta incluindo a velhice. 0 cuidado de si é para todos os indivíduos. O que faz com que sejam alteradas as condições que o determinam. 0 campo de aplicação passa a visar a todos, durante todo o tempo e sem condição de status. 0 objetivo a ser alcançado passa a ser a finalidade em si mesmo e não a cidade, como no período anterior. $E$ a forma principal passa a estar relacionada a uma prática de si e não mais ao conhecimento de si. (FOUCAULT, 2006).

No Quadro 1 observamos que o cuidado de si no momento da idade de ouro também é pautado por saberes filosóficos e médicos, todavia, destacam-se as ideias dos filósofos da época helenística (epicuristas, cínicos e estoicos), tais como Sêneca, Marco Aurélio, Frontão, Plíneo, Epicuro e Epicteto, além das ideias de Galeno. No que se refere às práticas, estas deveriam ser propagadas para toda a população. Observamos no Quadro 1 técnicas que já existiam em período anterior, mas que atingem seu auge nesse período, como a escrita. Há 
também a técnica da escuta, da leitura, da fala, além das técnicas que requerem concentração também, como a meditação, a memorização e o exame de consciência. Cabe ressaltar que a escuta é o primeiro procedimento na ascese e na subjetivação do discurso considerado verdadeiro (FOUCAULT, 2006; 2012c). Nas palavras do filósofo "[...] escutar é com efeito 0 primeiro passo, o primeiro procedimento na ascese e na subjetivação do discurso verdadeiro, uma vez que escutar, em uma cultura que sabemos bem ter sido fundamentalmente oral, é o que permitirá recolher o lógos, recolher o que se diz de verdadeiro" (FOUCAULT, 2006, p. 402).

Além das práticas citadas acima, deparamo-nos também com práticas relacionadas com a dieta, o regime, como pode ser identificado no livro: História da sexualidade 3: o cuidado de si. Essas práticas atreladas aos usos dos prazeres continuam associadas aos exercícios físicos, aos alimentos, às bebidas, ao sono e às relações sexuais. Foucault ressalta que:

[...] de um modo geral, todos esses temas da dietética permaneceram extraordinariamente contínuos desde a época clássica; os princípios gerais, como vemos, mantiveram-se os mesmos; no máximo, eles foram desenvolvidos, detalhados e aprimorados; eles propõem um ajuste da vida mais estrito e solicitam da parte daqueles que querem observá-los uma atenção ao corpo mais constantemente vigilante (FOUCAULT, 1985, p. 109).

Cuidar de si significa desenvolver uma arte da existência. Cuidar de si é considerado uma prática social que se desenvolve na relação com os outros. "Para que a prática de si alcance o eu por ele visado, o outro é indispensável" (FOUCAULT, 2006, p. 158).

Nesse contexto da idade de ouro há uma dissociação entre o conhecimento de si e o cuidado de si, pois o cuidado de si é fechado em si mesmo e não relacionado à cidade, à política, como anteriormente. Há o desenvolvimento de uma cultura de si. Destaca-se ainda que a concepção epicurista de amizade seja uma forma de cuidado de si, sendo um dos elementos da sabedoria e da felicidade. E a concepção estoica do homem comunitário contribui para que o cuidado de si se transforme em cuidado dos outros (FOUCAULT, 2006).

Nesse contexto, refuta-se a imagem do pião, pois este gira sobre si sob o impulso externo. A imagem do pião pode ser associada aos modelos que impõem regras de condutas. "O pião gira sobre si, mas gira sobre si justamente como não convém que giremos sobre nós. O que é o pião? É alguma coisa que gira sobre si por solicitação e sob o impulso de um movimento exterior" (FOUCAULT, 2006, p. 255).

Foucault, ao referir-se à problematização da imagem do pião, diz que:

Contrário ao movimento do pião, a sabedoria consistirá em não se deixar jamais ser induzido a um movimento involuntário por solicitação e impulso de um movimento exterior. Pelo contrário, será preciso buscar no centro de nós mesmos o ponto no qual nos fixaremos e em relação ao qual permaneceremos imóveis.

É na direção de si mesmo ou do centro de si (centro de si mesmo) que devemos fixar nossa meta (FOUCAULT, 2006, p. 255)

Contrário à imagem do pião, Sêneca apresenta a imagem do rodopio e defende a ideia de que o sujeito deve girar em torno de si mesmo, para se liberar. Diferentemente do pião, a imagem do rodopio nos leva a pensar na necessidade de resistir aos modelos que impõem regras de condutas. A imagem do rodopio suscita uma movimentação própria, que parta do próprio sujeito. 
Nesse sentido, observamos a subjetivação do discurso com o objetivo de constituição de si e não a confissão ou purificação, como na era cristã. Trata-se de se propor conselhos que permitam práticas de liberdade e não de escravidão (FOUCAULT, 2006; 2012c).

No momento cristão, III e IV d. C., o cuidado de si está relacionado à renúncia de si e não ao retorno a si, como na Antiguidade greco-romana. Nesse período se propõe 0 sacrifício, a renúncia a si em função de uma palavra dita por outro. 0 sujeito passa a ser guiado por meio da confissão cristã (FOUCAULT, 2012a; 2012b).

No Quadro 1 identificamos que o cuidado de si deixa de ser fundamentado pelos saberes filosóficos e médicos e passa a se embasar nos saberes religiosos, por meio dos textos cristãos, destacando-se o Traité de la virginité de Gregório de Nisa (FOUCAULT, 2012a). Com relação às práticas, apesar de se apresentarem com o mesmo nome de algumas da Antiguidade, como a escrita, a escuta, os exercícios de memória, de meditação e os exames de consciência, essas práticas se distinguem do modelo helenístico. Não se busca mais o uso dos prazeres (FOUCAULT, 2006).

No momento cristão, III e IV d.C. o cuidado de si está atrelado à renúncia a todas as ligações terrestres, a tudo o que pode ser reconhecido como apego ao si mesmo terrestre. Da Antiguidade para o Cristianismo há uma transformação de uma moral que era na sua essência a busca de uma ética pessoal para uma moral como obediência a um sistema de regras (FOUCAULT, 2012a; 2012b).

\section{REFLEXÕES PARA A EDUCAÇÃO FÍSICA}

Como a discussão sobre o cuidado de si em diferentes momentos sócio-históricos pode contribuir com a Educação Física na atualidade? Devemos retornar a esses períodos de maneira saudosista ou buscar elementos que possam trazer reflexões para os dias de hoje?

Pensamos que essa discussão possa contribuir para problematizar o reforço ao culto ao corpo e os imperativos da vida saudável na atualidade.

Observamos que a sociedade atual é uma sociedade das aparências, como mostra Soares (2008). A exacerbação do consumo oferece estímulos para a busca da perfeição corporal e do estilo de vida ativo, contribuindo com o reforço ao individualismo contemporâneo. "Parece que a aparência corporal torna-se, efetivamente, o último objeto de valorização íntima que se exibe como conquista individual" (SOARES, 2008, p. 82).

Para Sant'Anna (2005), essa melhoria da aparência que é visualizada na época atual é norteada por uma ordem tecnocientífico-empresarial e o marketing é considerado um elemento de controle social. Nesse contexto, cuidar de si hoje também está atrelado ao individualismo. A autora destaca que:

[...] se, por um lado, as singularidades de cada corpo são preteridas em favor das necessidades da economia de mercado, por outro, e para compensar um tal disparate , cada um tende a inflacionar o espaço dedicado aos cuidados de si com preocupações e ações totalmente voltadas para esse "si"; como se para cuidar desse "si" fosse preciso separá-lo do mundo, isolá-lo num spa ou num lugar que, como diria a publicidade, "tem a sua cara e o seu jeito de ser" (SANT'ANNA, 2005, p. 100). 
Ortega (2005) também tece reflexões sobre as práticas atuais e mostra que são práticas de assujeitamento e disciplinamento. Para esse autor, existe "[...] uma vontade de uniformidade, de adaptação à norma e de constituição de modos de existência conformistas e egoístas, visando a procura da saúde e do corpo perfeito" (ORTEGA, 2005, p. 142).

Diante do cenário atual, destacamos que a discussão realizada neste estudo possa contribuir com os cuidados com o corpo em busca de saúde tendo como fundamento o cuidado de si. Todavia, não a partir da busca de obediência a um sistema de regras como na era cristã, por meio da renúncia de si e do sacrifício, como podemos ler em Foucault (2006; 2012a; 2012b), ou até mesmo pela busca de obediência aos preceitos dos discursos biomédicos que também desejavam regular a vida dos indivíduos e da sociedade (FOUCAULT, 2001).

Concordamos com Ortega (2005) quando o autor demonstra a necessidade de se oferecer pontos de resistência aos dispositivos disciplinares. Para ele:

\section{[...] a autonomia, a liberdade e o poder sobre si que se desdobra no poder sobre os outros - características do indivíduo que faz a escolha de se con- stituir como sujeito moral, submetendo-se a uma ascese corporal e espiritual - constituem uma resposta às práticas subjetivantes modernas" (ORTEGA, 2005, p. 153).}

Nesse sentido, a imagem do rodopio proposta por Sêneca (FOUCAULT, 2006) deve ser enfatizada pela Educação Física. Uma imagem que reforça a ideia de que o sujeito deve girar em torno de si mesmo, contribuindo com a sua constituição. A imagem do rodopio contribui para despertar a criação de estratégias de resistência aos modelos que impõem regras de condutas e que estão implícitos nos ditames da vida saudável e do corpo perfeito. Pensamos que essa discussão possa contribuir com saberes e práticas que problematizem o culto ao corpo, num padrão de estilo de vida ativo permeado pela ideia do ser saudável ideal e que a Educação Física possa se lembrar da concepção epicurista de amizade e da concepção estoica do homem comunitário para proporcionar práticas comunicativas nas quais o cuidado de si se transforme em cuidado com os outros, a fim de problematizar 0 individualismo contemporâneo.

Nesse sentido, a Educação Física poderá proporcionar práticas de liberdade por meio do uso dos prazeres, seja por meio de técnicas de concentração ou por outras práticas corporais capazes de proporcionar uma prática refletida sobre si mesmo e de quem está ao seu redor, como podemos identificar em Foucault (2006; 2012a; 2012b). Todavia, de acordo com o contexto atual e específico em que os sujeitos estão inseridos.

Destacamos ainda que na atualidade os cuidados com o corpo em busca de saúde requerem a multidisciplinaridade, onde a escuta dos sujeitos é fundamental, mas que muitas vezes é deixada de lado, pois se enfatizam discursos e práticas permeados por ditames a serem seguidos e que quase sempre seguem os parâmetros biomédicos. Cabe lembrar que a escuta é uma das primeiras técnicas do cuidado de si da Antiguidade greco-romana, como pode ser identificado em Foucault (2006), e que necessita ser retomada nos dias de hoje.

\section{CONSIDERAÇÕES FINAIS}

A análise detalhada de alguns livros de Michel Foucault relacionados ao conceito de "cuidado de si" pode contribuir para ampliar o debate epistemológico na Educação Física no 
Brasil e a nível internacional. O conceito de cuidado de si religa saberes e práticas e pode ser reconhecido como um fundamento filosófico a ser tematizado na Educação Física.

Ressaltamos saberes e práticas associadas ao cuidado de si, nos seguintes momentos sócio-históricos: socrático-platônico, a idade de ouro nos séculos I e II d.C. e na passagem aos séculos IV e V d.C. Podemos observar pelo Quadro 1 e nas discussões realizadas que cada período tem suas especificidades, mesmo tendo elementos em comum. Das ideias filosóficas e médicas para as ideias religiosas. Das técnicas como práticas de liberdade da Antiguidade greco-romana para as técnicas como renúncia de si guiadas pela confissão cristã.

Após as discussões sobre o cuidado de si, apresentamos reflexões para a Educação Física. Destacamos a imagem do rodopio, no sentido de problematizar na atualidade os cuidados com o corpo em busca de saúde com base em padronizações e a obediência incondicional a esses ditames que são impostos de múltiplas maneiras e também problematizar preceitos que tenham a intenção de uma administração calculista da existência. A imagem do rodopio provoca a Educação Física a ter como desafio despertar práticas nas quais cada sujeito seja capaz de girar em torno de si. Práticas que contribuam com a sua própria constituição, ao invés de ditar normas fixas a serem seguidas sem qualquer tipo de reflexão.

\section{REFERÊNCIAS}

AYRES, José R.C.M. Cuidado e reconstrução das práticas de saúde. Interface, Botucatu, v. 8 , n. 14, p. 73-92, set. 2003/fev. 2004.

BEAULIEU, Alain. Les archives Foucault à Berkeley. Disponível em: <http://michel-foucaultarchives.org/sites/michel-foucault-archives.org//MG/pdf/FT-Berkeley.pdf >. Acesso em: 5 maio 2013.

BEZERRA, Hudson P. O. Corpo e saúde: reflexões sobre o quadro "Medida Certa". 2012. 206 f. Dissertação (Mestrado em Educação Física) - Universidade Federal do Rio Grande do Norte, Natal, 2012.

BOSSLE, Cibele B. O personal trainer e o cuidado de si: uma perspectiva de mediação profissional. Movimento, Porto Alegre, v. 14, n. 1, p. 187-198, 2008.

CANDIOTTO, Cesar. Ética e política em Michel Foucault. Trans/Form/Ação, Marília, v. 33, n. 2, p. 157-175, 2010.

CANDIOTTO, Cesar. Subjetividade e verdade no último Foucault. Trans/Form/Ação, Marília, v. 31, n. 1, p. 87-103, 2008.

CARVALHO, Yara M. O mito da atividade física e saúde. São Paulo: Hucitec, 1995.

CASTRO, Fausto Calaça Galvão de; VIANA, Terezinha de Camargo; BARA, Olivier. O "cuidado de si" em Platão e em Balzac: algumas páginas da história da subjetividade. Revista Mal-Estar e Subjetividade, Fortaleza, v. 10, n. 4, p. 1271-1300, dez. 2010.

ERIBON, Didier. Michel Foucault: 1926-1984. Tradução de Hildegard Feist. São Paulo:

Companhia das Letras, 1990. 
FARINA, Juliane Tagliari et al. A construção social do presente: ética, estética e política. Psico, Porto Alegre; v. 41, n. 3, p. 296-302, jul./set. 2010.

FENSTERSEIFER, Paulo E. Atividade epistemológica e educação física. In: NÓBREGA, Terezinha Petrúcia da. Epistemologia, saberes e práticas da educação física. João Pessoa: Editora da UFPB, 2006.

FONSECA, Márcio A. Entre a vida governada e o governo de si. In: ALBUQUERQUE JÚNIOR, Durval Muniz de; VEIGA NETO, Alfredo José da; SOUZA FILHO, Alípio de. (Org.). Cartografias de Foucault. Belo Horizonte: Autêntica, 2008. p. 241-251

FOUCAULT, Michel. A escrita de si. In: MOTTA, Manoel B. da (Org.). Ética, sexualidade, política: Michel Foucault. 3. ed. Rio de Janeiro: Forense Universitária, 2012c.

FOUCAULT, Michel. A ética do cuidado de si como prática da liberdade. In: MOTTA, Manoel B. da (Org.). Ética, sexualidade, política: Michel Foucault. 3. ed.. Rio de Janeiro: Forense Universitária, 2012a.

FOUCAULT, Michel. A hermenêutica do sujeito. São Paulo: Martins Fontes, 2006.

FOUCAULT, Michel. Discurso y verdad en la antígua Grécia. Barcelona: Paidós Ibérica, 2004.

FOUCAULT, Michel. História da Sexualidade 1: a vontade de saber. Rio de Janeiro: Edições Graal, 1988.

FOUCAULT, Michel. História da sexualidade 2: o uso dos prazeres. Rio de Janeiro: Graal, 1984.

FOUCAULT, Michel. História da sexualidade 3: o cuidado de si. Rio de Janeiro: Graal, 1985.

FOUCAULT, Michel. Le gouvernement de soi et des autres. Paris: Gallimard, 2008.

FOUCAULT, Michel. 0 nascimento da clínica. Rio de Janeiro: Forense Universitária, 2001.

FOUCAULT, Michel. Resumo dos cursos do Collège de France: 1970-1982. Rio de Janeiro: Zahar, 1997.

FOUCAULT, Michel. Uma estética da existência. In: MOTTA, Manoel B. da (Org.). Ética, sexualidade, política: Michel Foucault. 3. ed.. Rio de Janeiro: Forense Universitária, 2012b.

FRAGA, Alex Branco. Exercício da informação: governo dos corpos no mercado da vida ativa. São Paulo: Autores Associados, 2006.

GLEYSE, Jacques. L'instrumentalisation du corps: une archéologie de la rationalisation instrumentale du corps, de l'âge classique à l'époque hypermoderne. Paris: L'Harmattan, 1997.

GLEYSE, Jacques. La Renaissance de la "fabrication du corps" par l'exercice physique au XVle siècle: discours, pratique, préservation d'un patrimoine, ou transgression d'un interdit? une étude des archives du fonds ancien de la Faculté de medicine de Montpellier. Canadian Journal of History/Annales Canadiennes d'Histoire, Toronto, v. 46, n. 1, p. 1-33, 2011.

GOETZ, Rose. Paul Ricoeur et Michel Foucault. Le Portique, Paris, n. 13-14, p. 1-6, 2004.

GOMES, Ivan. M. Conselheiros modernos: propostas para a educação do indivíduo saudável. 
HÉNAFF, Nolwenn. Blog: um journal intime comme mémoire de soi. Conserveries Mémorielles, Québec et Paris, n. 10, p. 1-22, 2011.

LE BLAY, Frédéric. Une version pervertie de la connaissance de soi: le cas d'Hostius Quadra. Pallas, Toulouse, n. 92, p. 305-313, 2013.

LEITE, Lidiane; ARAGÃO, Elizabeth Maria Andrade. O exercício ético na constituição do sujeito político como cidadão. Fractal: Revista de Psicologia, Rio de Janeiro, v. 22, n. 3, p. 543-556, set./dez. 2010.

MACHADO, Leila D.; LAVRADOR, Maria Cristina C. Por uma clínica da expansão da vida. Interface, Botucatu, v. 13, p. 515-521, 2009. Supl. 1.

MOZÈRE, Liane. Le souci de soi chez Foucault et le souci dans une éthique politique du care. Le Portique, Paris, n. 13-14, p. 1-10, 2004.

MUCHAIL, Salma T. Foucault, simplesmente. São Paulo: Loyola, 2004.

NÓBREGA, Teresinha Petrúcia. Corporeidade e educação física: do corpo-objeto ao corposujeito. Natal: Editora da UFRN, 2000.

ORTEGA, Francisco. Da ascese à bio-ascese ou do corpo submetido à submissão do corpo. In: RAGO, Margareth; ORLANDI, Luiz B. L.; VEIGA-NETO, Alfredo. (Org.). Imagens de Foucault e Deleuze: ressonâncias nietzschianas. 2. ed.. Rio de Janeiro: DP\&A, 2005.

PALMEIRA, lací Proença; FERREIRA, Márcia de Assunção. O corpo que eu fui e o corpo que eu sou: concepções de mulheres com alterações causadas pela hanseníase.Texto contexto enfermagem, Florianópolis, v. 21, n. 2, p. 379-386, jun. 2012.

RESENDE, Catarina. A escrita de um corpo sem órgãos. Fractal: Revista de Psicologia, Rio de Janeiro, v. 20, n. 1, p. 65-76, jan./ jun. 2008.

SANT'ANNA, Denise B. Transformações do corpo: controle de si e uso dos prazeres. In: RAGO, Margareth; ORLANDI, Luiz B. L.; VEIGA-NETO, Alfredo (Org.). Imagens de Foucault e Deleuze: ressonâncias nietzschianas.2. ed.. Rio de Janeiro: DP\&A, 2005.

SEIXAS, Cristiane Marques; BIRMAN, Joel. O peso do patológico: biopolítica e vida nua. História, ciências, saúde-Manguinhos, Rio de Janeiro, v. 19, n. 1, p.13-26, mar. 2012.

SILVA, Ana Márcia. Corpo, ciência e mercado: reflexões acerca da gestação de um novo arquétipo da felicidade. São Paulo: Autores Associados, 2001.

SILVA, Irene de Jesus et al . Cuidado, autocuidado e cuidado de si: uma compreensão paradigmática para o cuidado de enfermagem. Revista da Escola de Enfermagem USP, São Paulo, v. 43, n. 3, p.697-703, set. 2009.

SOARES, Carmen Lúcia. A educação do corpo e o trabalho das aparências: o predomínio do olhar. In: ALBUQUERQUE JÚNIOR, Durval Muniz; VEIGA NETO, Alfredo; SOUZA FILHO, Alípio de. (Org.). Cartografias de Foucault. Belo Horizonte: Autêntica, 2008. p. 69-82.

SOARES, Carmen Lúcia. Educação Física: raízes europeias e Brasil. 2. ed.. Campinas,SP: Autores Associados, 2001. 
intensiva: comecemos por cuidar de nós. Revista Brasileira de Enfermagem, Brasília, v. 63, n. 6, p.956-963, nov./dez. 2010. 